\title{
Respiratory function following on-Pump versus off-pump coronary bypass grafting surgery
}

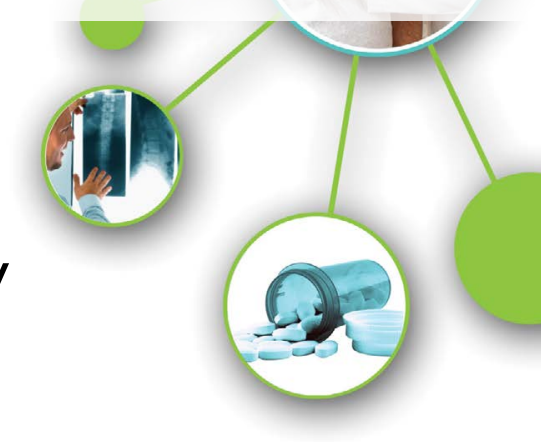

Objective: Respiratory dysfunction is a very common postoperative complication that occurs after cardiac surgery. Among the suggested causes is cardiopulmonary bypass. We compared the effect of on-pumpcoronary artery bypass grafting (ONCABG) versus off-pumpcoronary arterybypass grafting (OPCABG) on postoperative respiratory function.

Methods: Patients were prospectively divided into two groups ONCABG and OPCABG, ( $\mathrm{n}=100$ in each). Respiratory variables $\left(\mathrm{PaO}_{2}, \mathrm{PaCO}_{2}, \mathrm{SaO}_{2}\right.$, and $\mathrm{PaO}_{2} / \mathrm{FiO}_{2}$ ratio) were measured prior to induction of anaesthesia then at seven time points (ICU admission, postoperative hours 1, 3, 6, 12, 18, and 24). Time to extubation, rates of reintubation, and use of noninvasive ventilation (NIV) were also evaluated.

Results: Baseline preoperative arterial blood gases and alveolar/arterial oxygen pressure gradients were similar in both groups. Postoperatively, all values were significantly higher in the OPCABG group only at ICU admission $(p<0.05)$. No differences were seen in time to extubation, rate of reintubation rate, and use of postoperative NIV.

Conclusion: There is a slightly less incidence of lung injury with OPCABG as compared to ONCABG in low-risk patients especially in the early postoperative period.

Keywords: cardiac surgery, coronary bypass grafting, postoperative complications, respiratory function, PaO2/ FIO2 ratio, arterial blood gas

\section{Introduction}

Respiratory dysfunction is a common and well recognized postoperative complication that occurs early after open heart surgery [1]. It is associated with high mortality rates and manifests as decreased arterial oxygen partial pressure, atelectasis, pulmonary oedema, pleural effusion, pneumonia [2] or adult respiratory distress syndromeand may persist over the first days after surgery [3]. The main causes for occurrence of respiratory complications are the effects of sternotomy, internal mammary artery harvesting, pulmonary ischemia with subsequent reperfusion, as well as the inflammatory reaction caused by cardiopulmonary bypass (CPB) [1]. The risk of occurrence increases depending on several elements, including preoperative lung function [5] and smoking history [6], as well as intraoperative factors such as lung collapse during CPB [7]. The off-pump coronary artery bypass grafting (OPCABG) technique has been developed with the aim of avoiding or at least reducing some of the perioperative complications that may be related to the use of CPB [8].

There is growing evidence to support better outcomes and lower risk of occurrence of complications with the use of OPCABG as opposed to the standard on-pumpcoronary artery bypass grafting (ONCABG) technique [3,8-18]. Most of these studies however did not perform a detailed analysis of gas exchanges after coronary artery bypass grafting (CABG). In the current study we aimed to compare the effects of OPCABG and ONCABG on pulmonary gas exchange using controlled assessment of arterialo2 pressure (Pao2), arterial carbon dioxide pressure (Paco2), arterial $\mathrm{O}_{2}$ saturation $(\mathrm{SaO} 2)$ and ratio of arterial oxygen partial pressure to fractional inspired oxygen $\left(\mathrm{PaO}_{2} / \mathrm{FiO}_{2}\right)$ over the course of the first 24 hours following elective $C A B G$ surgery.

\section{Methods}

\section{- Participants}

200 patients aged between $30-70$ years
Mohamed Ali Bakry*1, Mohamed Elhassaini Abdelghafar Yousef ${ }^{2}$ \& Hisham Mohamed Mohamed Salem ${ }^{2}$

\section{${ }^{1}$ Department of Anesthesiology, Faculty of Medicine, Cairo University, ${ }^{2}$ Department of Anesthesia, Research Institute of Ophthalmology, Egypt \\ *Author for correspondence:}

mab628@kasralainy.edu.eg 
who underwent primary elective isolated CABG between 2014-2016 were enrolled in this study.

\section{- Exclusion criteria}

(a) patients undergoing emergency $C A B G$, (b) patients with acute or chronic lung disease(c)patients with depressed left ventricular function (ejection fraction $<40 \%$ ) (d) patients who had smoked in the preceding 6 months, (e) patients returning to the operating room within the first 24 hours, (f) patients with moderate and/or severe liver disease and (g) patients with preoperative organ support as defined by: (i) mechanical (intra-aortic balloon-pump [IABP]) or pharmacological hemodynamic support, (ii) renal support with any form of renal replacement therapy, and (ii) respiratory support with invasive or noninvasive ventilation (NIV).

The patients were randomly divided according to the use of intraoperative CPB into Group A (ONCABG) and Group B (OPCABG). Each group included 100 patients.

The study was approved by the local ethics committee and informed written consent was obtained from each patient.

\section{- Operative details}

Surgery was carried out through a median sternotomy. The standard cardiac anesthesia protocol used in our center was implemented. This entailed induction by midazolum and fentanyl or propofol and fentanyl with pancuronium bromide $0.1 \mathrm{mg} /$ $\mathrm{Kg}$ as the muscle relaxant. Maintenance of anesthesia was by volatile agents (isoflurane) and the mechanical ventilation settings were: tidal volume $5 \mathrm{ml} / \mathrm{kg}$ and respiratory rate $12 \mathrm{bpm}$. Analgesia was maintained using fentanyl boluses if needed.

In group $A$ (on-pump; ONCABG) surgery was carried out using $C P B$ with aortic cross clamping and cardioplegic arrest. Patients were disconnected from the ventilator during the procedure. In group B (off-pump; $O P C A B G)$ surgery was carried out using the commercially available coronary stabilizers [4].

After the surgery, in the intensive care unit (ICU), the ventilator was set at the synchronized intermittent mandatory ventilation + pressure support modality, with a default PEEP of $5 \mathrm{~cm} \mathrm{H}_{2} \mathrm{O}$ and tidal volumes kept in the range of 6 to $8 \mathrm{~mL} / \mathrm{kg}$ of ideal body weight.

\section{- Data collected}

I. Baseline data: (1) demographics: age, sex, height, weight, and body mass index (BMI); (2) preoperative status: diabetes, hypertension, hypercholesterolemia, smoking history, creatinine, left ventricular (LV) and right ventricular (RV) systolic function, especially the LV systolic function which was classified according to the ejection fraction as good $(>55 \%)$, mildly impaired (46\%-55\%), moderately impaired (36\%-45\%), or severely impaired $(<35 \%)$; and (4) baseline arterial blood gas analyses while the subjects were breathing room air spontaneously prior to induction of anesthesia.

II. Operative data: including operating and total intubation time and total hospital stay.

III. Postoperative data: (1) arterial oxygen tension $\left(\mathrm{PaO}_{2}\right),(2)$ carbon dioxide tension $\left(\mathrm{PaCO}_{2}\right) ;(3)$ arterial $\mathrm{O}_{2}$ saturation $\left(\mathrm{SaO}_{2}\right)$; (4)ratio of arterial oxygen partial pressure to fractional inspired oxygen $\left(\mathrm{PaO}_{2} / \mathrm{FiO}_{2}\right)$ (5)time to extubation and need for early reintubation (within the first 24 hours) and (6) use of any form of noninvasive ventilation support NIV support after extubation within the first 24 hours. These parameters were collected at seven time points: time of admission to the ICU and at postoperative hours 1, 3, $6,12,18$, and 24 .

\section{Statistical Analysis}

Descriptive statistical analysis was used and the results are presented as mean \pm SD. The $t$ test was used for comparison of continuous variables between the two groups and the Chi-square test or the Fisher's exact test was used for categorical variables.Pearson's correlation was used to explore relationships between quantitative variables.A two-sided $P<0.05$ was considered significant for all comparisons.

\section{Results}

As demonstrated in TABLE 1, there were 
Table 1. Demographic and clinical characteristics of critically ill elderly patients $(\mathrm{N}=154)$.

\begin{tabular}{|c|c|c|c|}
\hline \multicolumn{2}{|l|}{ Characteristic } & $\begin{array}{c}\text { Group A: ONCABG } \\
(n=100)\end{array}$ & $\begin{array}{c}\text { Group B: OPCABG } \\
(n=100)\end{array}$ \\
\hline \multirow{10}{*}{$\begin{array}{l}\text { Demographics } \\
\text { and Baseline } \\
\text { parameters }\end{array}$} & Age (year) & $60.1 \pm 11.5$ & $59.8 \pm 12.6$ \\
\hline & Gender M/F & $78 / 22$ & $84 / 16$ \\
\hline & Height $(\mathrm{cm})$ & $170.6 \pm 5.9$ & $168.4 \pm 7.3$ \\
\hline & Weight (kg) & $83.6 \pm 11.5$ & $79.4 \pm 9.7$ \\
\hline & $\mathrm{BMI}\left(\mathrm{kg} / \mathrm{m}^{2}\right)$ & $29.1 \pm 4.0$ & $28.3 \pm 3.8$ \\
\hline & Hypertension (\%) & 76.1 & 74.9 \\
\hline & Creatinine $(\mu \mathrm{mol} / \mathrm{L})$ & $90.1 \pm 8.6$ & $94.6 \pm 7.2$ \\
\hline & Hypercholestrolemia (\%) & 87.9 & 88.8 \\
\hline & Diabetes (\%) & 57.6 & 62.0 \\
\hline & Former smoker (\%) & 64 & 71 \\
\hline \multirow{7}{*}{$\begin{array}{l}\text { Preoperative } \\
\text { Respiratory } \\
\text { Functions }\end{array}$} & Good RV systolic function (\%) & 92.6 & 91.8 \\
\hline & Good LV systolic function (\%) & 87.9 & 89.3 \\
\hline & Ejection fraction (\%) & $58.6 \pm 9.3$ & $60.6 \pm 8.1$ \\
\hline & $\mathrm{PaO}_{2}(\mathrm{mmHg})$ & $83.5 \pm 20.1$ & $82.6 \pm 21.9$ \\
\hline & $\mathrm{PaCO}_{2}(\mathrm{mmHg})$ & $36.4 \pm 4.5$ & $39.6 \pm 3.4$ \\
\hline & $\mathrm{SaO}_{2}(\%)$ & $92.6 \pm 11.4$ & $93.7 \pm 9.1$ \\
\hline & $\mathrm{PaO}_{2} / \mathrm{FiO}_{2}$ ratio & $344.2 \pm 20.3$ & $326.1 \pm 27.1$ \\
\hline \multirow{9}{*}{$\begin{array}{l}\text { Operative } \\
\text { Characteristics }\end{array}$} & Operating time (mins) & $181.1 \pm 31.1$ & $167.6 \pm 35.3$ \\
\hline & Aortic cross clamping time (mins) & $28 \pm 4.8$ & $\mathrm{~N} / \mathrm{A}$ \\
\hline & Number of grafts performed & $3.6 \pm 0.1$ & $3 . .0 \pm 0.4$ \\
\hline & Internal mammary artery use (\%) & 100 & 100 \\
\hline & Intubation time (hours) & $7.1 \pm 6.5$ & $6.9 \pm 5.8$ \\
\hline & Patients requiring reintubation (\%) & 3 & 1 \\
\hline & Patients requiring NIV (\%) & 15 & 14 \\
\hline & Blood transfusion (units) & $1.6 \pm 0.3$ & $1.0 \pm 0.3$ \\
\hline & Hospital stay (days) & $6.4 \pm 0.7$ & $5.6 \pm 0.9$ \\
\hline
\end{tabular}
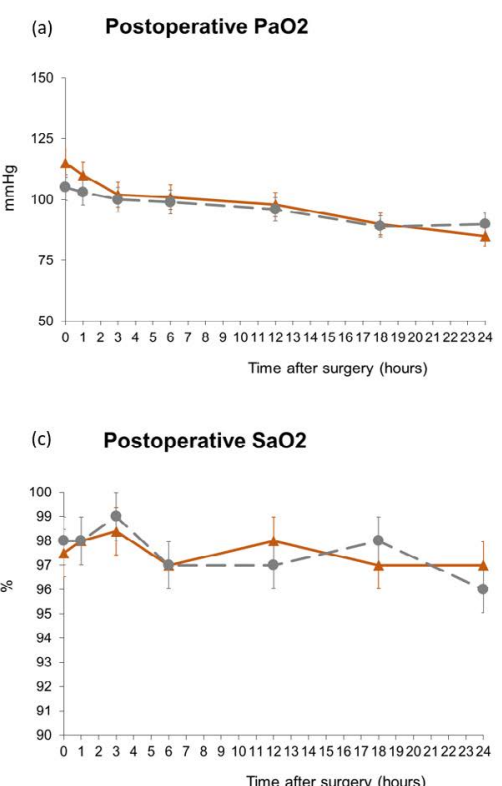
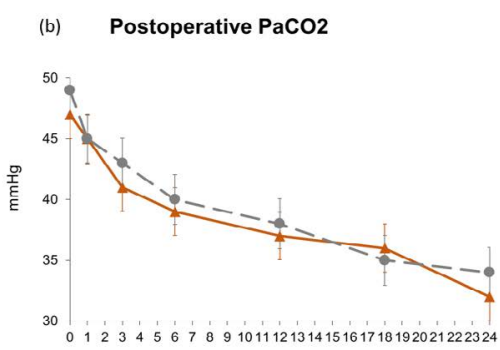

Time after surgery (hours)

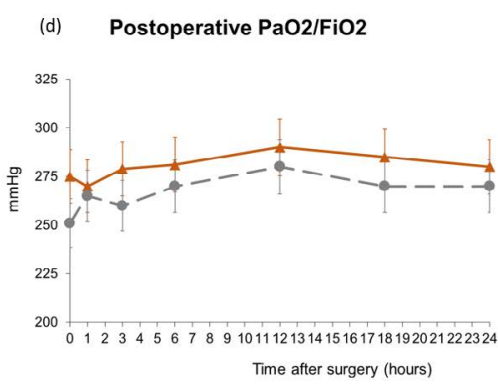

$\neq$ Group A (ONCABG) $\rightarrow$. Group B (OPCABG)

FIGURE 1.Graphs showing (a) mean PaO2 values ( $\mathrm{mm} \mathrm{Hg}$ ), (b) mean $\mathrm{PaCO} 2$ values ( $\mathrm{mm} \mathrm{Hg}$ ), (c) mean $\mathrm{SaO} 2$ values (\%) and (d) mean Pao2/Fio2 ratio values at each postoperative time point starting from the time of admission to intensive care unit (ICU), along with $95 \%$ confidence interval (error bars) the two groups (Group A; ONCABG and Group B; OPCABG).

ONCABG, on-pump coronary artery bypass grafting; OPCABG, off-pump coronary artery bypass grafting. PaCO2: partial pressure of arterial carbon dioxide; $\mathrm{PaO2}$ : partial pressure of arterial oxygen; $\mathrm{PaO2} / \mathrm{FiO2}$ : ratio of arterial oxygen partial pressure to fractional inspired oxygen; SaO2: arterial oxygen saturation. 
no significant differences between the two groupsand they were comparable in terms of demographic and clinical characteristics as well as the surgical procedures performed. There were also no differences in intubation times or need for blood transfusion. We did observe ahigher number of grafts performed as well as longer hospital stay periods in the ONCABG group. There was also a trend toward more patients with good systolic functions in the OPCABG group but these differences were small and statistically insignificant. All of the patients progressed well following surgery and both groups were comparable in terms of need for reintubation or the postoperative use of NIV.

FIGURE 1 shows the results of arterial blood gas analyses alveolar/arterial oxygen pressure gradients for the two groups measured at the seven time points over the course of the first 24 hours postoperatively, with zero indicating time of admission to the ICU.

The most noteworthy observation is that significant differences between the two groups were only found at the zero time point i.e. upon admission to the ICU. At this time point, significantly higher $\mathrm{PaO}_{2}$ and $\mathrm{PaO}_{2} / \mathrm{FiO}_{2}$ values were found in Group $\mathrm{B}$ (the OPCABG group). Also at this time point a significantly higher $\mathrm{PaCO}_{2}$ value was found in group $A$ (ONCABG group). Other than that, no other significant difference in the overall course of $\mathrm{PaO}_{2}, \mathrm{PaCO}_{2}$ and $\mathrm{PaO}_{2} / \mathrm{FiO}_{2}$ values and no differences in $\mathrm{SaO}_{2}$ values were observed at any time point over the course of the first 24 hours spent in ICU.

\section{Discussion}

In the current study we performed a detailed evaluation of respiratory function; specifically gas exchange sequentially over the course of the first postoperative 24 hours following $C A B G$ surgery. The only other study that performed such a detailed analysis of these measures to compare the postoperative respiratory profile between OPCABG and ONCABG surgery did so retrospectively, by going through what was available in the records of the patients saved in their database [3]. To our knowledge our study is the first study that prospectively collected these data to specifically evaluate the differences between the on-pump versus off-pump technique with the aim of detecting the potential advantages of OPCABG.

We found similar values in oxygenation both overall and at most time points. The only significant differences were observed at ICU admission, with seemingly better arterial perfusion in the OPCABG group. Similar findings were also reported by Chiarenza and his colleagues [3]. It is important to note that in concordance with our study they too noted that this difference was not observed at any other time point throughout the course of the first 24 hours postoperatively and therefore cannot be taken as indication of higher risk of lung injury with ONCABG. They postulated that the most likely explanation for a difference only on ICU admission is in homogeneities in ventilation during transfer of the patients from the operating room to the ICU as they are ventilated with aambu bag [3]. This does not explain why better arterial gas characteristics on ICU admission were only seen in the OPCABG group in both studies with two completely independent study cohorts and surgical teams. It could be that there is very mild intraoperative lung damage associated with the ONCABG technique which is rapidly compensated and does not cause permanent deficit. The effect of OPCABG on pulmonary function is still unclear. While large randomized studies have found no benefit using OPCABG compared to ONCABG [9-11] and several smaller studies have also found no significant differences in pulmonary gas exchange, time to extubation, or postoperative pulmonary function between on-pump and off-pump CABG patients $[8,18-23]$ there are reports of improved static and dynamic lung compliance, reduced rates of respiratory complications, and shorter intubation times in OPCABG patients [19,24-29]. The authors of these studies proposed better preservation of pulmonary function as an explanation for this $[20,25,27,30]$.

In the current study, we used a noninvasive yet sensitive measure of pulmonary gas exchange to conduct a controlled comparison between the effects of on-pump and off-pump CABG. Our results can therefore be reliably taken to indicate 
that there is no advantage using off-pump over on-pump CABG in terms of early postoperative pulmonary gas exchange in non-smoking (at least for the preceding 6 months) patients with good left ventricular function and no preexisting lung disease. This is further supported by the lack of difference in number of patients requiring reintubation and/or NIV postoperatively between the two groups. This suggests a very limited role for CPB in the occurrence of postoperative pulmonary dysfunction, and that other factors are responsible for the development of lung injury during CABG. These factors may include general anesthesia as well as interstitial edema which can cause serious mechanical and gas exchange abnormalities [4,31]. It is important to note however that the $\mathrm{PaO}_{2} / \mathrm{FiO}_{2}$ ratio maintained values within the range of acute lung injury
[32] throughout the first postoperative day, confirming the presence of a lung insult even in elective low-risk patients undergoing cardiac surgery, regardless of the use of CPB. Similar findings were reported previously $[3,18]$. High risk patients were excluded from our studies thus it is difficult to speculate if a larger difference in the postoperative course of respiratory variables would have been found in a population at higher risk (such as more-than-mild chronic obstructive pulmonary disease or patients undergoing emergency $(A B G)$. This needs to be addressed by future studies.

\section{Acknowledgements}

The authors wish to thank the surgeons, ICU doctors and nurses and lab technicians for their help and Ms Fatima Mohamed and Ms Mariam Ibrahim for help with patient rexcruitment and data organization. 


\section{REFERENCES}

Filsoufi, F, Rahmanian, PB, Castillo, JG, Chikwe, J, Adams DH. Predictors and early and late outcomes of respiratory failure in contemporary cardiac surgery. Chest. 133(3), 13-721 (2008).

Jensen, L, Yang, L. Risk factors for postoperative pulmonary complications in coronary artery bypass graft surgery patients. Eur. J. Cardiovasc. Nurs. 6(3), 241-246 (2007).

Chiarenza F, Tsoutsouras T, Cassisi C, et al. The Effects of On-Pump and OffPump Coronary Artery Bypass Surgery on Respiratory Function in the Early Postoperative Period. J. Intensive Care Med.6(3): 241-246 (2017).

Wan S, Izzat MB, Lee TW, et al. Avoiding cardiopulmonary bypass in multivessel CABG reduces cytokine response and myocardial injury. Ann. Thorac. Surg. 68(1), 52-57 (1999).

Nissinen J, Biancari F, Wistbacka JO. Pulmonary function and immediate and late outcome after coronary artery bypass surgery. J. Cardiovasc. Surg. (Torino) 51(6), 915-921 (2016).

Santos NP, Mitsunag, RM, Borges DL. Factors associated to hypoxemia in patients undergoing coronary artery bypass grafting. Rev. Bras. Cir. Cardiovasc. 28(3), 364-370 (2013).

Cislaghi F, Condemi AM, Corona A. Predictors of prolonged mechanical ventilation in a cohort of 3,269 CABG patients. Minerva Anestesiol. 73(12), 615-621(2007).

Izzat MB, Almohammad F, Raslan AF. Off-pump grafting does not reduce postoperative pulmonary dysfunction. Asian Cardiovasc. Thorac. Ann. 25(2), 113-117 (2017).

Diegeler A, BorgermannJ, Kappert $U$. Off-pump versus on-pumpcoronaryarterybypass grafting in elderly patients. N. Engl. J. Med. 368(13), 1189-198.

Lamy A, Devereaux PJ, Prabhakaran D. Off-pump or on-pumpcoronaryarterybypass grafting at 30 days. N. Engl. J. Med. 366(16), 1489-1497 (2012).
Shroyer AL, Grover FL, Hattler B. On-pump versus off-pumpcoronaryarterybypass surgery. N. Engl. J. Med. 361(19), 1827-1837 (2009).

Mack MJ, Pfister A, Bachandn D. Comparison of coronary bypass surgery with and without cardiopulmonary bypass in patients with multivessel disease. J. Thorac Cardiovasc. Surg. 127(1), 167-173 (2004).

Kara I, Cakalagaoglu C, Ay Y. Reoperative coronary artery bypass surgery: the role of on-pump and offpump techniques on factors affecting hospital mortality and morbidity. Ann. Thorac. Cardiovasc. Surg. 19(6), 435440 (2013).

Sa MP, Lima LP, Rueda FG. Comparative study between onpump and off-pump coronary artery bypass graft in women. Rev. Bras. Cir. Cardiovasc. 25(2), 238-244 (2010).

Narayan P, Caputo M, Jones J, et al. Postoperative chest radiographic changes after on- and offpumpcoronary surgery. Clin. Radiol. 60(6), 693-699 (2005).

Engels GE, Gu YJ, van Oeveren W, et al. The utility of lung epithelium specific biomarkers in cardiac surgery: a comparison of biomarker profiles in onand off-pumpcoronary bypass surgery. J. Cardiothorac. Surg. 8,4 (2013).

Angdin M, Settergren G, Vaage J. Better preserved pulmonary endothelium-dependent vasodilation with off-pumpcoronary surgery. Scand. Cardiovasc. J. 35(4), 264-269 (2001).

Montes FR, Maldonado JD, Paez S, Ariza F. Off-pump versus on-pump coronary artery bypass surgery and postoperative pulmonary dysfunction. J. Cardiothorac. Vasc. Anesth. 18(6), 698-703 (2004).

Kochamba GS, Yun KL, Pfeffer TA, Sintek CF, Khonsari S. Pulmonary abnormalities after coronary arterial bypass grafting operation: cardiopulmonary bypass versus mechanical stabilization. Ann. Thorac. Surg. 69(5): 1466-1470 (2000).

Boyd WD, Desai ND, Del Rizzo DF, et al. Off-pump surgery decreases postoperative complications and resource utilization in the elderly. Ann. Thorac. Surg. 68(4): 1490-1493 (1999).

Møller $\mathrm{CH}$, Perko MJ, Lund JT, et al. No major differences in 30day outcomes in high-risk patients randomized to off-pump versus onpump coronary bypass surgery. The Best Bypass Surgery Trial. Circulation. 121(4), 498-504 (2010).

Sarin EL, Kayatta MO, Kilgo $\mathrm{P}$, et al. Short- and longterm outcomes in octogenarian patients undergoing offpump coronary artery bypass grafting compared with on-pump coronary artery bypass grafting. Innovations (Phila). 6(2), 110-115 (2011).

Groeneveld $A B$, Jansen $E K$ and Verheij J. Mechanisms of pulmonary dysfunction after on-pump and offpump cardiac surgery: a prospective cohort study. J. Cardiothorac. Surg. 11 (2007).

Meharwal Z, Mishra Y, Kohli V, et al. Off-pump multivessel coronary artery surgery in high-risk patients. Ann. Thorac. Surg. 74(4),S1353-S1357.

Gu" ler M, Kirali K, Toker ME. Different CABG methods in patients with chronic obstructive pulmonary disease. Ann. Thorac. Surg. 71(1),152-157 (2001).

Lamy A, Devereaux PJ, Prabhakaran D. Off-pump or on-pump coronary artery bypass grafting at 30 days. . Engl. J. Med. 366(16), 1489-1497 (2012).

Ohkado A, Nakano K, Nakatani H, et al. The superiority of pulmonary function after minimally invasive direct coronary artery bypass. Jpn. J. Thorac. Cardiovasc. Surg. 50(2),66-69 (2002).

LaPar DJ, Bhamidipati CM, Reece $T B$, et al. Is off-pump coronary artery bypass grafting superior to conventional bypass in octogenarians? J. Thorac. Cardiovasc. Surg. 141(1), 810890 (2011).

Pawlaczyk R, Swietlik D, Lango R, Rogowski J. Offpump coronary surgery may reduce stroke, respiratory failure and mortality in octogenarians. Ann. Thorac. Surg. 94 (1), 29-37 (2012). 
Moshkovitz Y, Lusky A and Mohr R. Coronary artery bypass without cardiopulmonary bypass: analysis of short-term and mid-term outcome in 220 patients. J. Thorac. Cardiovasc.
Surg. 110 (4),979-987 (1995).

Young RW. Prevention of lung injury in cardiac surgery: a review. J Extra Corpor Technol. 46(2), 130-141 (2014).
Ferguson, ND, Fan, E, Camporota, L. The Berlin definition of ARDS: an expanded rationale, justification, and supplementary material. Intensiv. Care. Med. 38(10), 1573-1582 (2012). 